Published in final edited form as:

Gastroenterology. 2007 December ; 133(6): 1840-1848.

\title{
Inactivation of the UNC5C netrin-1 receptor is associated with tumor progression in colorectal malignancies
}

\author{
Agnès Bernet $1,{ }^{1}$, , Laetitia Mazelin $1,{ }^{*}$, Marie-May Coissieux ${ }^{1}$, Nicolas Gadot $^{2}$, Susan L. \\ Ackerman $^{3}$, Jean-Yves Scoazec ${ }^{2,4, \$}$, and Patrick Mehlen $1,5, \$$ \\ 1 Apoptosis, Cancer and Development Laboratory-Equipe labellisée 'La Ligue', CNRS UMR5238, University \\ of Lyon, Centre Léon Bérard, 69008 Lyon, France
}

2ANIPATH, Génopole Rhône-Alpes/Université Lyon 1, Faculté Laennec, 69372, Lyon, France

3The Jackson Laboratory, 600 Main Street, Bar Harbor, Maine, 04609, USA

4INSERM, U45, IFR62, University of Lyon, 69372 Lyon, France

5The Buck Institute for Age Research, Novato, CA, USA

\section{Abstract}

Background \& Aims-The UNC5H netrin-1 receptors (UNC5H1-3, or UNC5A-C) belong to the functional dependence receptors family that share the ability to induce apoptosis in the absence of their ligands. Such a trait has been hypothesized to confer a tumor suppressor activity. Indeed, cells harboring these receptors are thought to be dependent on ligand availability for their survival, thereby inhibiting uncontrolled tumor cell proliferation. We investigate here whether UNC5C acts as a tumor suppressor in colorectal malignancies.

\begin{abstract}
Methods-The level of UNC5C was analyzed in a panel of 86 primary sporadic colorectal carcinomas. Loss of heterozygosity in the UNC5C locus and epigenetic alterations in the UNC5C promoter were also analyzed. Intestinal tumor progression was monitored in mice bearing both UNC5C and APC $1638 \mathrm{~N}$ mutations and apoptosis was measured in intestinal tumors developed in UNC5C/APC ${ }^{1638 N}$ mutant mice.
\end{abstract}

Results-We show here that UNC5C expression is down-regulated in a large fraction of human colorectal cancers, mainly through promoter methylation. Moreover, in mice, inactivation of UNC5C is associated with increased intestinal tumor progression and a decrease in tumor cell apoptosis.

Conclusion-We demonstrate here that the loss of UNC5C expression observed in human colorectal cancer is a selective advantage for tumor progression, in agreement with the dependence receptor hypothesis. Thus, the UNC5C dependence receptor is a tumor suppressor that regulates sporadic colorectal cancer.

Corresponding author: P. Mehlen; Tel: 33478782870- Fax: 33478782887; e-mail: mehlen@lyon.fnclcc.fr.

These authors contributed equally to this work

$\$$ co-senior authors

No conflicts of interest exist

Publisher's Disclaimer: This is a PDF file of an unedited manuscript that has been accepted for publication. As a service to our customers we are providing this early version of the manuscript. The manuscript will undergo copyediting, typesetting, and review of the resulting proof before it is published in its final citable form. Please note that during the production process errors may be discovered which could affect the content, and all legal disclaimers that apply to the journal pertain. 


\section{Background \& Aims}

Netrin-1, a diffusible laminin-related protein, plays a major role in the control of neuronal navigation during the development of the nervous system by interacting with its main receptors, DCC (Deleted in Colorectal Cancer) 123 and UNC5H 4, 5 . However, more recently, netrin-1 has emerged as a completely different molecule regulating cell survival: indeed, DCC and $\mathrm{UNC} 5 \mathrm{H}$, (UNC5H1, UNC5H2, and UNC5H3 also called UNC5A, UNC5B and UNC5C) belong to the so-called dependence receptor family 67 .

Dependence receptors, which also include RET ${ }^{8}$, Patched ${ }^{9}$, some integrins ${ }^{10}$, neogenin 11 and $75^{\mathrm{NTR}} 12$, share the functional property of inducing cell death when disengaged from their ligands, whereas their pro-apoptotic activity is blocked in the presence of their ligand. These receptors thus create cellular states of dependence on their respective ligands 13,14 . The molecular mechanisms used by these unbound receptors to trigger apoptosis are in large part unknown, yet it appears that their cleavage by caspases is required for cell death induction, as it allows the exposure/release of a pro-apoptotic domain that in turn induces apoptosis 6 15 . Other mechanisms, including interaction with pro-apoptotic proteins like DAPK or NRAGE have also been proposed $16,17$.

The pro-apoptotic activity of unbound dependence receptors has so far mainly been observed in vitro, and has been suggested to act as a means of eliminating tumor cells that would develop in settings of ligand unavailability, such as proliferation of tumor cells in a cell environment with constant and limited ligand presence or migration of metastatic tumor cells in tissues where the ligand is absent. This hypothesis fits with the observation that both the DCC and UNC5H genes are down-regulated in tumors, thereby suggesting that their loss represents a selective advantage for tumor development 18,1920 . However, the only in vivo evidence so far to confirm this model is that netrin-1 overexpression in the mouse gastrointestinal tract leads to tumor initiation and progression ${ }^{21}$. Whereas this observation suggests that one or several netrin-1 receptors act(s) as tumor suppressor(s), it falls short of (i) mimicking the human disease, as netrin-1 rarely seems to be over-expressed in human colorectal tumors 21 and (ii) demonstrating per se that one of these dependence receptors acts as a true tumor suppressor.

DCC was proposed in the early 1990s to be a tumor suppressor gene mainly associated with the later stages of intestinal tumor development ${ }^{19}$. A large number of subsequent reports support the implication of DCC in colorectal tumor suppression (for a review see ${ }^{22}$ ). However, very few mutations in DCC have been detected in cancer and especially in hereditary cancer diseases, and both heterozygous and homozygous inactivations of DCC in mice have failed to show increased tumor initiation or progression ${ }^{23}$, therefore, DCC's role as a tumor suppressor is still unclear.

Here we investigate whether UNC5H3/UNC5C acts as a tumor suppressor in colorectal malignancies. We first demonstrate that expression of the UNC5C gene is down-regulated in colorectal cancers, mainly because of tumor-associated specific promoter methylation. We also show that inactivation of UNC5C in mice is associated with increased intestinal tumor progression and decreased tumor cell apoptosis. These data, taken together with human data on loss of UNC5C pro-apoptotic activity in colorectal cancers, are strongly in support of the UNC5C dependence receptor being a tumor suppressor.

\section{Methods}

A detailed methods section is provided in supplementary materials 


\section{Cell line and reagents}

Colorectal cancer cell lines HCT116, SW480, HCT-15, SW48, LoVo, LS174T, Caco-2, TC7, and Co115 were previously described. The HCT116 double knock-out for DNMT1 and DNMT3b were described previously and were kindly provided by B. Vogelstein 24 . HCT116 or SW480 colorectal tumor cells were treated with $5 \mu \mathrm{M} 5$-Aza-2'-deoxycytidine (Sigma Aldrich) $24 \mathrm{~h}$ after plating, treatment was replenished every $24 \mathrm{~h}$ during $48 \mathrm{~h} .0 .3 \mu \mathrm{M}$ Trichostatin A (ICN) was then added during $24 \mathrm{~h}$.

\section{Quantitative real-time RT-PCR and Laser Capture Microdissection}

To assay UNC5C expression in human colorectal tumors, total RNA was extracted from biopsies of patients undergoing surgery for colorectal cancer, as described in the supplementary materials. The ubiquitously expressed RxR $\alpha$, PPIA and GAPDH genes, showing the less variability in expression between normal and colorectal tumoral tissues, were used as internal controls. Moreover, 8 other ordinarily housekeeping genes were also used to strengthen the results: $\beta$-actin, Phosphoglycerokinase 1(PGK), $\beta 2$-microglobulin, Hypoxanthine ribosyltransferase (HPRT), TATA-box-binding protein (TBP), Porphobilinogen deaminase (PBGD), Transferin receptor (TfR), ribosomal protein large P0 (RPLP0). Laser capture was performed under direct microscopic visualization using a PixCell II LCM system (Arcturus, Mountain View, CA) on $16 \mu$ m-thick tissue frozen sections prepared from colon tumor and normal biopsies stained with KIT0415 HistoGene staining solution (Arcturus) as described in supplementary materials.

\section{LOH analysis}

Genomic DNA (50ng) from matched tumor and corresponding normal tissue was amplified by PCR and analysed as described ${ }^{18}$, using fluorescently labeled primers for the indicated polymorphic microsatellite markers on chromosomes 4q21-23 for UNC5C locus. At the difference of Thiebault et al., markers D4S470, D4S1174, D4S1218 were excluded from the study because they were not adequate. Two closer (one inside the gene) and more significant markers designed in our laboratory called $\mathrm{C} 1$ and $\mathrm{C} 2$ inside were selected and respectively amplified using primers: C1For5'CTCCTCCTCCATGCTTTCAG3' and C1Rev5' GTTTCCATTATGTTTTGTTGGAAAG3', C2insideFor5' TTCCAGCAAAGGACACATCA3' and C2insideRev5' GTTTGGAAAAGAGATCTGCTCA3'.

\section{UNC5C promoter methylation analysis}

Methylation-specific PCR (MSP) analysis of sodium-bisulfite-treated DNA from human colorectal biopsies of normal and tumoral tissues was performed as described in supplementary materials. The UNC5C promoter region, amplified from the bisulfite-modified DNA by PCR was also sequenced as described in supplementary materials.

\section{Mice breeding, genotyping and tumor analysis}

$\mathrm{UNC} \mathrm{C}^{\mathrm{RCM}}$ and Apc ${ }^{+/ 1638 \mathrm{~N}}$ mice were described previously 421 and mice genotyping is described in supplementary materials. All animals were used in hybrid $\mathrm{B} 6 / \mathrm{C} 3 \mathrm{H}$ genetic background and specific attention was paid to using animals issued of similar crosses for the studies on tumor progression. Indeed, the distribution in low grade/high grade adenoma or adenocarcinoma varies significantly, depending on the genetic background studied and breeding conditions. UNC5 $\mathrm{C}^{\mathrm{rcm} / \mathrm{rcm}}$ and wild type animals were killed at 20 months of age. $\mathrm{Apc}^{+/ 1638 \mathrm{~N}} \mathrm{UNC} \mathrm{C}^{+/+}, \mathrm{Apc}^{+/ 1638 \mathrm{~N}} \mathrm{UNC} \mathrm{C}^{+/ \mathrm{rcm}}, \mathrm{Apc}^{+/ 1638 \mathrm{~N}} \mathrm{UNC}^{\mathrm{rcm} / \mathrm{rcm}}$ mice were killed at a similar age: 6 months. Histological classification and grading of neoplastic lesions was performed in a blinded fashion similarly to 21 and as described in supplementary materials. 


\section{Apoptosis, Proliferation and differentiation scoring}

Apoptosis, proliferation and differentiation scoring was performed essentially as before 21 and as described in supplementary materials.

\section{In situ hybridization}

Specific DIG-labelled sense and antisense RNA probes corresponding to human UNC5C cDNA were generated according to the methods described in the Roche "DIG RNA labelling kit" and as described in the supplementary materials.

\section{Results}

\section{Epithelial expression of UNC5C is down-regulated in human colorectal cancers}

In initial studies, we analyzed whether UNC5C is expressed in normal colonic epithelium. In situ hybridizations performed on human colon show that UNC5C is expressed in the colonic epithelium (Fig.1A, panels abc). We next investigated whether UNC5C shows a decreased expression in human colorectal cancers. UNC5C expression was analyzed by real-time Q-RTPCR in a panel of 86 colorectal tumors versus corresponding normal tissues. As shown in Fig. $1 \mathrm{BCD}$, a reduction in UNC5C expression was detected in more than $74 \%$ of colorectal tumors, with $45 \%$ of tumors showing more than a 10 fold reduction. UNC5C expression reduction was also detected by in situ hybridization (Fig.1A, panel d). To discard a potential bias of heterogeneity in tumor/normal tissue samples, epithelial cells from tumor/normal tissue were laser micro-dissected and assessed for UNC5C expression by real-time Q-RT-PCR. In the 4 pairs of samples assessed, an important decrease in UNC5C expression was detected in tumor cells (in 3 sample pairs the loss of UNC5C was actually amplified compared to crude samples) (Fig.1E), demonstrating per se that human colorectal cancer is associated with a loss of UNC5C expression specifically in tumor cells. Interestingly, by comparing the reduction in UNC5C in a fraction of the tested tumors with available clinical charts (43 on 86) of corresponding patients, we observed that loss of UNC5C is associated with tumor progression and aggressiveness (Fig.2 and Supplementary Fig.1). However, even though this correlation is statistically significant, a larger scale study remains to be performed to further demonstrate that loss of UNC5C is a marker for colorectal tumor progression.

\section{UNC5C expression is inhibited via tumor associated UNC5C promoter methylation}

Searching for the mechanisms that may explain such down-regulation, we analyzed whether loss of expression was associated with loss of heterozygosity ( $\mathrm{LOH}$ ) at the UNC5C locus. As previously described, $\mathrm{LOH}$ in UNC5C was found in some tumors with reduced UNC5H levels (18 and not shown). However, the relatively low occurrence of LOH at the UNC5C locus (25-35\% depending on the microsatellite markers used -see Experimental procedures-) suggested an alternative mechanism for UNC5C loss of expression in colorectal tumors. This prompted our search for UNC5C promoter methylation. While UNC5C expression is hardly detectable in numerous colorectal cancer cell lines (not shown, list in the Methods section), treatment with the methylation inhibitor 5-aza-2'-deoxycytidine (5aza2dC) led to a robust increase of UNC5C expression in both colorectal HCT116 or SW480 cells. Moreover, cotreatment with 5aza2dC and trichostatin A (TSA), a specific inhibitor of the histone deacetylases that interact with methylated $\mathrm{CpGs}{ }^{25}$, massively turns on UNC5C transcription (Fig.3A). To discard drug toxicity, expression of UNC5C was analyzed in HCT116 cells with a double knock-out for both DNMT1 and DNMT3b, two crucial DNA methyltransferases 24. As shown in Fig.3B, UNC5C expression was more than 130 times higher in the double knock-out HCT-116 cells than in wild-type HCT116 cells, demonstrating the role of DNA methylation in UNC5C regulation. To further determine whether this methylation process is specifically associated with tumor development, we analyzed UNC5C promoter methylation 
in a panel of 18 colorectal tumors versus adjacent normal tissues. Putative $\mathrm{CpG}$ islands found in the UNC5C promoter region were investigated for methylation by Methylation Specific PCR (MSP). As shown in Fig.3C, 78\% of the tumor samples showed methylation in the UNC5C promoter, as compared to no methylation in the corresponding normal tissue. The MSP results were confirmed by direct sequencing of $\mathrm{CpG}$ islands in the UNC5C promoter region, including that of the first exon in 3 pairs of tumor/normal tissues in which down-regulation of UNC5C had been previously observed. Indeed, we observed that the UNC5C promoter region is highly methylated in the tumor samples, while no methylation occurs in normal tissues (Fig.3D and not shown). Thus, UNC5C expression is lost or highly decreased in colorectal tumors through specific tumor-associated promoter methylation.

\section{Inactivation of UNC5C is associated with tumor progression in mice}

Loss of UNC5C expression and the known inhibitory effect of UNC5C on hallmarks of cell transformation in vitro -anchorage-independent growth and invasion- 18 were suggestive of a putative UNC5C tumor suppressor activity. To further investigate this in vivo, we studied whether mutations in UNC5C were associated with tumor predisposition in mice. RCM (Rostral Cerebellum Malformation) mice have been shown to display a natural loss-of-function mutation in UNC5C, mainly associated with developmental problems in the cerebellum ${ }^{4}$. Interestingly, while inactivation of the other netrin-1 receptors encoding genes $-D C C$, $U N C 5 H A / 1, U N C 5 H B / 2$ - in mice is associated with embryonic lethality, $\mathrm{UNC}^{\mathrm{r}} \mathrm{C}^{\mathrm{rcm}}$ mutant mice go through adulthood. We first analyzed spontaneous tumor development. However, we failed to detect any obvious intestinal tumor development when compared to control mice, hence suggesting that UNC5C inactivation in mice is not a sufficient genetic event to trigger tumor initiation (not shown). We then investigated whether UNC5C inactivation affects tumor progression. UNC5 $\mathrm{C}^{\mathrm{rcm}}$ mice were backcrossed to an $\mathrm{Apc}^{+/ 1638 \mathrm{~N}}$ genetic background ${ }^{26}$. APC mutations exist in the vast majority of human colorectal tumors, and in mice, specific Apc mutations trigger the formation of tumors in the gastrointestinal tract -mainly low-grade adenomas but also, albeit at a smaller extent, more aggressive tumors, depending on the genetic background and animal breeding 23,2627 .. In the genetic background studied here, the number of neoplastic lesions per control ( $\mathrm{Apc}{ }^{+/ 1638 \mathrm{~N}} \mathrm{UNC} \mathrm{C}^{+/+}$) mouse was 1.13 , with a predominance of low-grade adenomas (Fig.4A). A striking difference was observed, however, in $\mathrm{Apc}^{+/ 1638 \mathrm{~N}} \mathrm{UNC}^{-1 / \mathrm{rcm}}$ and Apc ${ }^{+/ 1638 \mathrm{~N}} \mathrm{UNC} \mathrm{C}^{\mathrm{rcm} / \mathrm{rcm}}$ mice (Fig. 4). Although these mice displayed an overall frequency of neoplastic lesions similar to Apc ${ }^{+/ 1638 \mathrm{~N}}$ mice $-\mathrm{a}$ slight increase that was not statistically significant-, they showed a dramatic shift of low-grade adenomas towards higher grade tumors (low grade tumors: $71 \%$ (12 tumors out of 17) $\left(\mathrm{UNC} \mathrm{C}^{+/+}\right)$vs. $43 \%(36 / 83)\left(\mathrm{UNC} \mathrm{C}^{+/ \mathrm{rcm}}\right)$ vs. $17 \%(5 / 30)\left(\mathrm{UNC} 5 \mathrm{C}^{\mathrm{rcm} / \mathrm{rcm}}\right)$, significance of the overall differences between $\mathrm{UNC} 5 \mathrm{C}^{+/+}$and $\left.\mathrm{UNC} 5 \mathrm{C}^{\mathrm{rcm} / \mathrm{rcm}}: \mathrm{p}<0.001\right)$. The shift appears to occur both at the level of high grade adenoma (6\% (1/17) $\left(\mathrm{UNC}^{+/++}\right)$vs $40 \%(12 / 30)$ $\left(\mathrm{UNC} 5 \mathrm{C}^{\mathrm{rcm} / \mathrm{rcm}}\right)$ ) and at the level of higher grade lesions, fulfilling all the histological criteria for an adenocarcinoma diagnosis (Fig.4F), including stroma formation and signs of local invasion (involving the submucosa in most cases and the muscularis propria in some, $\left.{ }^{28}\right)(23 \%$ (4/17) $\left(\mathrm{UNC}^{+/+}\right)$vs 43\% (13/30) (UNC5 $\left.\mathrm{C}^{\mathrm{rcm} / \mathrm{rcm}}\right)$ ). Thus, UNC5C inactivation is associated with enhanced tumor stage in the presence of an Apc mutation, demonstrating per se that UNC5C loss-of-function is a selective advantage for tumor progression. Interestingly, a gradual higher grade tumor development occurs from $\mathrm{UNC} 5 \mathrm{C}^{+/+}$to $\mathrm{UNC} 5 \mathrm{C}^{+/ \mathrm{rcm}}$ and to UNC5 $\mathrm{C}^{\mathrm{rcm} / \mathrm{rcm}}$ mice, suggesting an inverse correlation between the level of functional UNC5C and tumor progression.

\section{UNC5C inactivation is associated with a reduction in apoptosis in mice tumors}

In an attempt to identify whether this increased tumor progression susceptibility was due to increased proliferation or to decreased apoptosis, we analyzed proliferation/differentiation/cell death in the intestinal tract of $\mathrm{UNC} 5 \mathrm{C}^{+/+}$or $\mathrm{UNC} 5 \mathrm{C}^{\mathrm{rcm} / \mathrm{rcm}}$ mice. No obvious change was 
observed, neither in differentiation, as determined by numbering goblet cells (Suppl Fig.2AB), nor in proliferation, as measured by BrdU incorporation (Suppl Fig.2CD), nor in cell death, as determined by counting cells with apoptotic morphology (not shown). In contrast, when analyzing the proliferation/apoptosis status in tumors from either $\mathrm{Apc}^{+/ 1638 \mathrm{~N}} \mathrm{UNC}^{\mathrm{C}} \mathrm{C}^{+/+}$, $\mathrm{Apc}^{+/ 1638 \mathrm{~N}} \mathrm{UNC}^{+} \mathrm{C}^{+/ \mathrm{rcm}}$ or Apc ${ }^{+/ 1638 \mathrm{~N}} \mathrm{UNC} \mathrm{C}^{\mathrm{rcm} / \mathrm{rcm}}$ mice, an interesting observation was made. While the number of proliferative cells was not affected when comparing same grade tumors (Suppl Fig.2E), a significant reduction in the number of apoptotic cells was detected in adenomas and adenocarcinomas from UNC5C mutant animals (Fig.5). In particular, whereas in adenocarcinomas from $\mathrm{Apc}^{+/ 1638 \mathrm{~N}} \mathrm{UNC} \mathrm{C}^{+/+}$mice, islets of cells undergoing apoptosis were frequently detected, very few were observed in adenocarcinomas from $\mathrm{Apc}^{+/ 1638 \mathrm{~N}}$ $\mathrm{UNC} \mathrm{C}^{+/ \mathrm{rcm}}$ and $\mathrm{Apc}^{+/ 1638 \mathrm{~N}} \mathrm{UNC} \mathrm{C}^{\mathrm{rcm} / \mathrm{rcm}}$ mice (Fig.5). It is therefore tempting to speculate that progression from low-grade adenoma towards high grade adenoma or adenocarcinoma associated with UNC5C loss-of-function occurs through loss of apoptosis induction, as would be expected following the dependence receptor hypothesis.

\section{Conclusion}

Here we present evidence that UNC5C is a tumor suppressor gene lost in the vast majority of human colorectal tumors. UNC5C loss-of-function in mice is associated with tumor progression. In agreement with the dependence receptor model, we have shown here that losing UNC5C in order to survive in settings of netrin-1 limitation would be a selective advantage for a tumor cell. In the human pathology, this selective advantage appears to be achieved at low frequency by $\mathrm{LOH}$ or at a much larger extent by promoter methylation.

Together with the fact that overexpression of netrin-1 in mouse gastrointestinal tract is associated with tumor initiation and progression 21 , these results give support to the view that the UNC5C/netrin-1 pair acts as a rheostat, regulating colorectal tumorigenesis. Receptor lossof-function or gain of its ligand have a similar effect on tumor development, strongly supporting the notion that dependence receptors regulate tumorigenesis by eliminating tumor cells through apoptosis.

It is however interesting to note that while netrin-1 overexpression in the gut was associated with a reduction of apoptosis in the intestinal epithelium ${ }^{21}$, no such effect was observed in the intestinal epithelium of UNC5C mutant mice. One can speculate that this difference is related to an alternative role of UNC5C, independent of its dependence receptor activity. $\mathrm{UNC} 5 \mathrm{H}$ receptors were indeed initially proposed to be involved in cell migration during embryonic development, as shown with neuronal migration especially 29 . However, such a migratory activity remains to be shown in adult tissue. Recently, UNC5B/H2 was also shown to be a negative regulator of embryonic vascularisation ${ }^{30}$. However, UNC5C is not expressed in endothelial cells, and neither netrin-1 nor UNC5C mutant mice showed obvious defects in vasculature formation. Thus, it is tempting to speculate that the increased tumor progression detected here is related to the pro-apoptotic function of UNC5C. Along this line, the observed increased frequency of adenocarcinomas associated with UNC5C loss-of-function and decreased apoptosis in these surnumerary adenocarcinomas strongly suggest that the effect seen on tumor progression is due to loss of UNC5C pro-apoptotic activity. The difference in the apoptotic status of transgenic netrin-1 mice normal intestinal epithelium and that of UNC5C mutant mice could rather be explained by the fact that, while overexpression of netrin- 1 blocks apoptosis of all the netrin-1 dependence receptors -DCC and UNC5A,B,C-, loss of UNC5C should only affect UNC5C-induced cell death. Along this line, while netrin-1 overexpression affects both tumor initiation (i.e., spontaneous adenoma formation) and progression (i.e., shift toward high-grade adenoma and adenocarcinoma when associated with the Apc mutation), loss of UNC5C appears to affect only tumor progression. This would also suggest that not only 
UNC5C, but other netrin-1 dependence receptors, such as DCC, UNC5A/H1 or UNC5B/H2, also play an important role as tumor suppressors in colorectal cancer.

Almost nothing is known on $\mathrm{UNC} 5 \mathrm{~A} / \mathrm{H} 1$ and $\mathrm{UNC} 5 \mathrm{~B} / \mathrm{H} 2$ regarding their possible implications in cancer, except that the $U N C 5 B$ gene has been shown to be a direct transcriptional target of p53 and, as such, able to mediate part of p53 pro-apoptotic activity ${ }^{31}$. On the opposite, DCC was proposed in the early 1990s to be a tumor suppressor gene. Loss of DCC expression was mainly associated with human colorectal tumor development ${ }^{19}$, and a large number of subsequent reports support the implication of DCC in colorectal tumor suppression (for a review see ${ }^{22}$ ). Yet, in large part because Fazeli and colleagues showed that DCC heterozygous mutant mice only display a modest, non significant increase in intestinal tumors and that homozygous inactivation of DCC in mice in an APCmin background does not lead to increased tumor progression ${ }^{23}$, serious doubts about DCC's role have been raised. If the controversy on DCC is still open, and most probably requires the analysis of additional mice models, it is interesting to note that both DCC and UNC5C appear to be down-regulated in later stages of colorectal malignancy. Indeed, decreased DCC expression was mainly associated with later stages of intestinal tumor development ${ }^{19}$ and in most studies, DCC has been considered as a marker of poor prognosis 3233 . Here, even though a larger scale study remains to be performed, we observe that decreased UNC5C expression is associated with stage III-IV tumors. Thus, UNC5C may turn out to be an interesting marker for colorectal malignancies.

\section{Supplementary Material}

Refer to Web version on PubMed Central for supplementary material.

\section{Acknowledgements}

We wish to thank C Rey for the help on laser microdissection, B. Vogelstein, R. Fodde and S. Robine for materials, S. Tavtigian for LOH studies, P.H Romeo, A. Chedotal, L. Pays and R. Dante for precious advice and H. Bilak for text correction.

Grant support: This work was supported by the Ligue Contre le Cancer (to PM), the NIH (NS45093, to PM), the FRM (PM), the ARC (PM), the Region Rhone-Alpes and the Canceropole CLARA (to PM, JYS) and the Institut National du Cancer (INCA) (to PM and JYS).

\section{References}

1. Serafini T, Colamarino SA, Leonardo ED, Wang H, Beddington R, Skarnes WC, Tessier-Lavigne M. Netrin-1 is required for commissural axon guidance in the developing vertebrate nervous system. Cell 1996;87:1001-14. [PubMed: 8978605]

2. Keino-Masu K, Masu M, Hinck L, Leonardo ED, Chan SS, Culotti JG, Tessier-Lavigne M. Deleted in Colorectal Cancer (DCC) encodes a netrin receptor. Cell 1996;87:175-85. [PubMed: 8861902]

3. Forcet C, Stein E, Pays L, Corset V, Llambi F, Tessier-Lavigne M, Mehlen P. Netrin-1-mediated axon outgrowth requires deleted in colorectal cancer-dependent MAPK activation. Nature 2002;417:4437. [PubMed: 11986622]

4. Ackerman SL, Kozak LP, Przyborski SA, Rund LA, Boyer BB, Knowles BB. The mouse rostral cerebellar malformation gene encodes an UNC-5-like protein. Nature 1997;386:838-42. [PubMed: 9126743]

5. Hong K, Hinck L, Nishiyama M, Poo MM, Tessier-Lavigne M, Stein E. A ligand-gated association between cytoplasmic domains of UNC5 and DCC family receptors converts netrin-induced growth cone attraction to repulsion. Cell 1999;97:927-41. [PubMed: 10399920]

6. Mehlen P, Rabizadeh S, Snipas SJ, Assa-Munt N, Salvesen GS, Bredesen DE. The DCC gene product induces apoptosis by a mechanism requiring receptor proteolysis. Nature 1998;395:801-4. [PubMed: 9796814]

7. Llambi F, Causeret F, Bloch-Gallego E, Mehlen P. Netrin-1 acts as a survival factor via its receptors UNC5H and DCC. Embo J 2001;20:2715-22. [PubMed: 11387206] 
8. Bordeaux MC, Forcet C, Granger L, Corset V, Bidaud C, Billaud M, Bredesen DE, Edery P, Mehlen P. The RET proto-oncogene induces apoptosis: a novel mechanism for Hirschsprung disease. Embo J 2000;19:4056-63. [PubMed: 10921886]

9. Thibert C, Teillet MA, Lapointe F, Mazelin L, Le Douarin NM, Mehlen P. Inhibition of neuroepithelial patched-induced apoptosis by sonic hedgehog. Science 2003;301:843-6. [PubMed: 12907805]

10. Stupack DG, Puente XS, Boutsaboualoy S, Storgard CM, Cheresh DA. Apoptosis of adherent cells by recruitment of caspase-8 to unligated integrins. J Cell Biol 2001;155:459-70. [PubMed: 11684710]

11. Matsunaga E, Tauszig-Delamasure S, Monnier PP, Mueller BK, Strittmatter SM, Mehlen P, Chedotal A. RGM and its receptor neogenin regulate neuronal survival. Nat Cell Biol 2004;6:749-55. [PubMed: 15258591]

12. Rabizadeh S, Oh J, Zhong LT, Yang J, Bitler CM, Butcher LL, Bredesen DE. Induction of apoptosis by the low-affinity NGF receptor. Science 1993;261:345-8. [PubMed: 8332899]

13. Mehlen P, Thibert C. Dependence receptors: between life and death. Cell Mol Life Sci 2004;61:185466. [PubMed: 15289929]

14. Bredesen DE, Mehlen P, Rabizadeh S. Receptors that mediate cellular dependence. Cell Death Differ 2005;12:1031-43. [PubMed: 16015380]

15. Mehlen P, Bredesen DE. The dependence receptor hypothesis. Apoptosis 2004;9:37-49. [PubMed: 14739597]

16. Williams ME, Strickland P, Watanabe K, Hinck L. UNC5H1 induces apoptosis via its juxtamembrane domain through an interaction with NRAGE. J Biol Chem 2003;278:17483-17490. [PubMed: 12598531]

17. Llambi F, Lourenco FC, Gozuacik D, Guix C, Pays L, Del Rio G, Kimchi A, Mehlen P. The dependence receptor UNC5H2 mediates apoptosis through DAP-kinase. Embo J 2005;24:1192-201. [PubMed: 15729359]

18. Thiebault K, Mazelin L, Pays L, Llambi F, Joly MO, Saurin JC, Scoazec JY, Romeo G, Mehlen P. The netrin-1 receptors UNC5H are putative tumor suppressors controlling cell death commitment. Proc Natl Acad Sci U S A 2003;100:4173-4178. [PubMed: 12655055]

19. Fearon ER, Cho KR, Nigro JM, Kern SE, Simons JW, Ruppert JM, Hamilton SR, Preisinger AC, Thomas G, Kinzler KW, et al. Identification of a chromosome 18q gene that is altered in colorectal cancers. Science 1990;247:49-56. [PubMed: 2294591]

20. Kinzler KW, Vogelstein B. Lessons from hereditary colorectal cancer. Cell 1996;87:159-70. [PubMed: 8861899]

21. Mazelin L, Bernet A, Bonod-Bidaud C, Pays L, Arnaud S, Gespach C, Bredesen DE, Scoazec JY, Mehlen P. Netrin-1 controls colorectal tumorigenesis by regulating apoptosis. Nature 2004;431:804. [PubMed: 15343335]

22. Mehlen P, Fearon ER. Role of the dependence receptor DCC in colorectal cancer pathogenesis. J Clin Oncol 2004;22:3420-8. [PubMed: 15310786]

23. Fazeli A, Dickinson SL, Hermiston ML, Tighe RV, Steen RG, Small CG, Stoeckli ET, Keino-Masu K, Masu M, Rayburn H, Simons J, Bronson RT, Gordon JI, Tessier-Lavigne M, Weinberg RA. Phenotype of mice lacking functional Deleted in colorectal cancer (Dcc) gene. Nature 1997;386:796804. [PubMed: 9126737]

24. Rhee I, Bachman KE, Park BH, Jair KW, Yen RW, Schuebel KE, Cui H, Feinberg AP, Lengauer C, Kinzler KW, Baylin SB, Vogelstein B. DNMT1 and DNMT3b cooperate to silence genes in human cancer cells. Nature 2002;416:552-6. [PubMed: 11932749]

25. Bird AP, Wolffe AP. Methylation-induced repression--belts, braces, and chromatin. Cell 1999;99:451-4. [PubMed: 10589672]

26. Fodde R, Edelmann W, Yang K, van Leeuwen C, Carlson C, Renault B, Breukel C, Alt E, Lipkin M, Khan PM, et al. A targeted chain-termination mutation in the mouse Apc gene results in multiple intestinal tumors. Proc Natl Acad Sci U S A 1994;91:8969-73. [PubMed: 8090754]

27. Takaku K, Oshima M, Miyoshi H, Matsui M, Seldin MF, Taketo MM. Intestinal tumorigenesis in compound mutant mice of both Dpc4 (Smad4) and Apc genes. Cell 1998;92:645-56. [PubMed: 9506519] 
28. Boivin GP, Washington K, Yang K, Ward JM, Pretlow TP, Russell R, Besselsen DG, Godfrey VL, Doetschman T, Dove WF, Pitot HC, Halberg RB, Itzkowitz SH, Groden J, Coffey RJ. Pathology of mouse models of intestinal cancer: consensus report and recommendations. Gastroenterology 2003;124:762-77. [PubMed: 12612914]

29. Mehlen P, Furne C. Netrin-1: when a neuronal guidance cue turns out to be a regulator of tumorigenesis. Cell Mol Life Sci 2005;62:2599-2616. [PubMed: 16158190]

30. Lu X, Le Noble F, Yuan L, Jiang Q, De Lafarge B, Sugiyama D, Breant C, Claes F, De Smet F, Thomas JL, Autiero M, Carmeliet P, Tessier-Lavigne M, Eichmann A. The netrin receptor UNC5B mediates guidance events controlling morphogenesis of the vascular system. Nature 2004;432:17986. [PubMed: 15510105]

31. Tanikawa C, Matsuda K, Fukuda S, Nakamura Y, Arakawa H. p53RDL1 regulates p53-dependent apoptosis. Nat Cell Biol 2003;5:216-23. [PubMed: 12598906]

32. Shibata D, Reale MA, Lavin P, Silverman M, Fearon ER, Steele G Jr, Jessup JM, Loda M, Summerhayes IC. The DCC protein and prognosis in colorectal cancer. N Engl J Med 1996;335:1727-32. [PubMed: 8929264]

33. Sun XF, Rutten S, Zhang H, Nordenskjold B. Expression of the deleted in colorectal cancer gene is related to prognosis in DNA diploid and low proliferative colorectal adenocarcinoma. J Clin Oncol 1999;17:1745-50. [PubMed: 10561211]

34. Latil A, Chene L, Cochant-Priollet B, Mangin P, Fournier G, Berthon P, Cussenot O. Quantification of expression of netrins, slits and their receptors in human prostate tumors. Int J Cancer 2003;103:306-15. [PubMed: 12471613]

35. Feroze-Merzoug F, Berquin IM, Dey J, Chen YQ. Peptidylprolyl isomerase A (PPIA) as a preferred internal control over GAPDH and beta-actin in quantitative RNA analyses. Biotechniques 2002;32:776-8. 780, 782. [PubMed: 11962599]

36. Blanquicett C, Johnson MR, Heslin M, Diasio RB. Housekeeping gene variability in normal and carcinomatous colorectal and liver tissues: applications in pharmacogenomic gene expression studies. Anal Biochem 2002;303:209-14. [PubMed: 11950223]

37. Feilchenfeldt J, Brundler MA, Soravia C, Totsch M, Meier CA. Peroxisome proliferator-activated receptors (PPARs) and associated transcription factors in colon cancer: reduced expression of PPARgamma-coactivator 1 (PGC-1). Cancer Lett 2004;203:25-33. [PubMed: 14670614]

38. de Kok JB, Roelofs RW, Giesendorf BA, Pennings JL, Waas ET, Feuth T, Swinkels DW, Span PN. Normalization of gene expression measurements in tumor tissues: comparison of 13 endogenous control genes. Lab Invest 2005;85:154-9. [PubMed: 15543203]

39. American Joint Committee on Cancer: AJCC Cancer Staging Manual. 5th. Philadelphia: Pa: Lippincott-Raven Publishers; 1997. Colon and rectum; p. 83-90. 
A

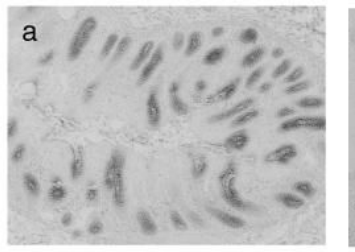

\section{b}

c

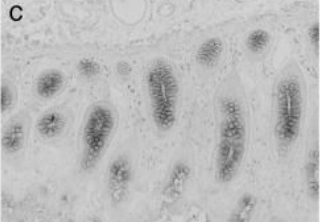

d
B

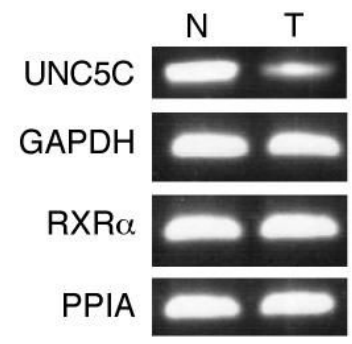

D

\begin{tabular}{|c|c|c|}
\hline \multicolumn{3}{|c|}{ \% of tumors $(\mathrm{n}=86)$ with down-expression of } \\
UNC5C greater than \\
2 fold & 5 fold & 10 fold \\
\hline 74 & 59 & 45 \\
\hline
\end{tabular}

C

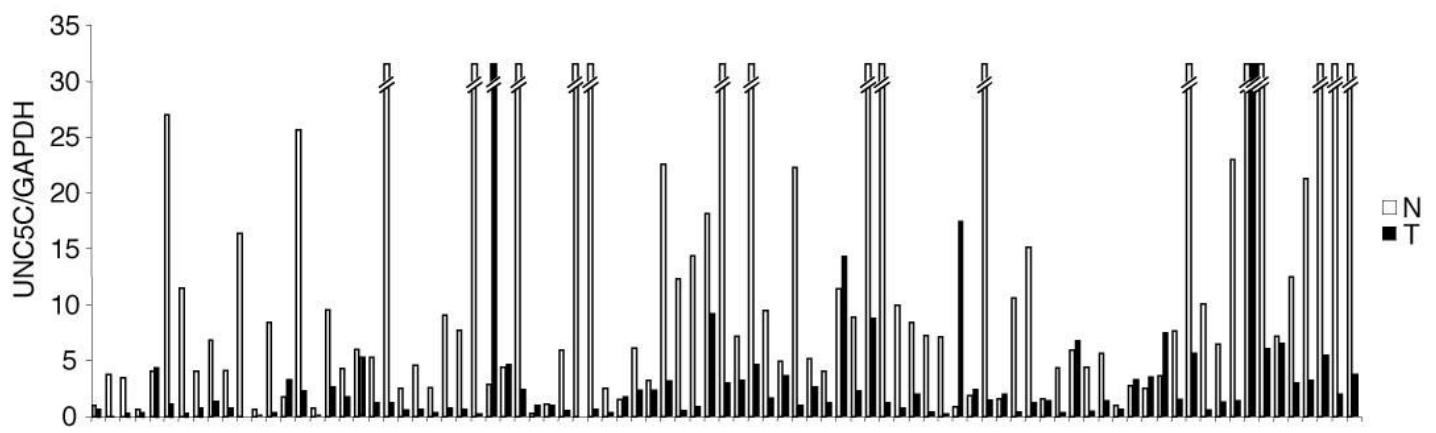

E

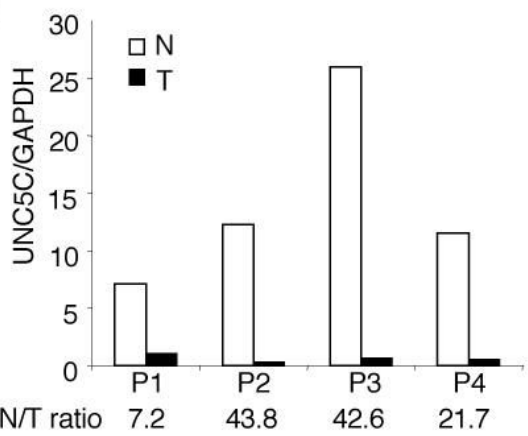

prior LCM
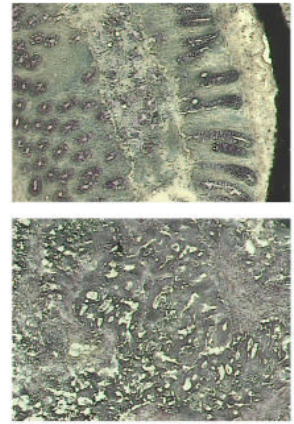

after LCM

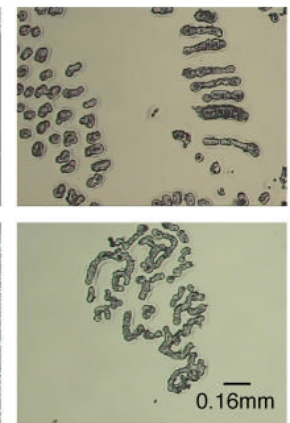

Figure 1. Loss of UNC5C expression in colorectal tumors

A, In situ hybridization performed in human colon on UNC5C. a: antisense probe on normal colon, b: sense probe, c: enlargement of a, d: antisense probe on adjacent tumor. Original magnifications: X50 (a,b,d), X100 (c). B,C,D, Quantitative real-time RT-PCR was performed using total RNA extracted from normal $(\mathrm{N})$ and tumoral $(\mathrm{T})$ tissues with specific human UNC5C primers 34 and eleven couples of specific human genes primers showing the less variability in their expression between normal and colorectal tumoral tissues, as described in 35, 363738 (see Experimental procedures section). B, A PCR in the exponential phase of a representative pair tumor/normal tissue is shown. $\mathbf{C}$, The expression levels in 86 colorectal 
tumors $(\mathrm{T})$ and corresponding normal tissue $(\mathrm{N})$ are given only as the ratio between UNC5C and GAPDH. Similar results were obtained with 10 other housekeeping genes described in Experimental procedures $\mathbf{D}$, The percentage of patients showing a loss of UNC5C expression in tumor compared to normal tissue is indicated. $\mathbf{E}$, Laser capture microdissection (LCM) was performed on 4 pairs of tumor/normal tissues and UNC5C expression was determined as in (B). Left: The expression levels in 4 colorectal tumors (T) and corresponding normal tissue (N) are given only as the ratio between UNC5C and GAPDH. Similar results were obtained with the other housekeeping RXR $\alpha$, PPIA genes. Right: typical microscopic visualization of LCM on colon section from human normal $(\mathrm{N})$ or tumoral biopsies $(\mathrm{T})$. Sections are shown prior to LCM, and after LCM, as the captured material is confirmed under microscopic visualization prior to processing for RNA extraction. 


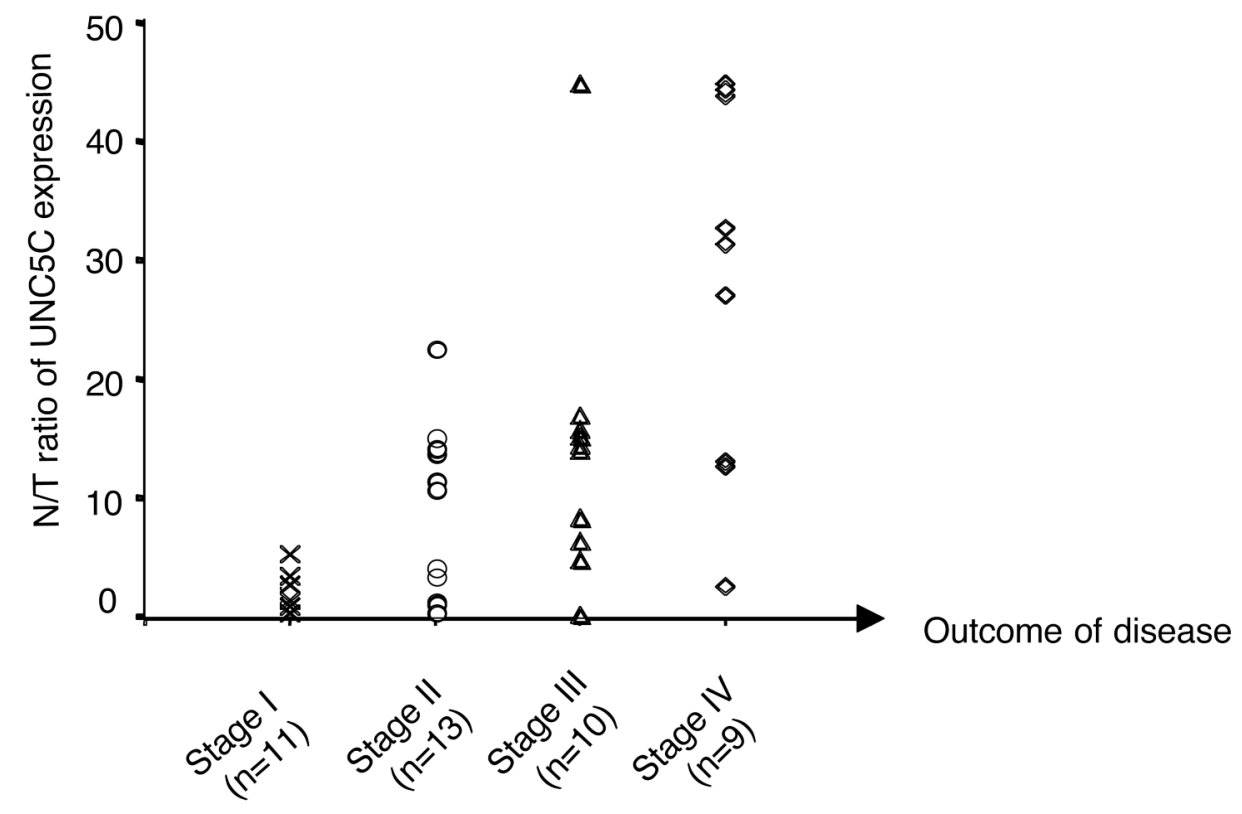

Figure 2. Correlation between patient clinical features and UNC5C expression N/T ratio in a limited panel of patient Correlation between UNC5C expression N/T ratio and $\mathrm{TNM}^{39}$ status classified in 4 stages from good to poor prognosis i.e. stage I (T1 or T2, N0M0), stage II (T3 or T4, N0M0), stage III (any T, N+M0) and stage IV (any T, any N, M+) ${ }^{39}$. A Kruskall-Wallis test was used comparing the overall panel, $\mathrm{p}=0.001$. A Mann-Whitney test was also used to compare stage I to stage IV $(\mathrm{p}=0.001)$, stage II to stage IV $(\mathrm{p}=0.004)$. The difference between stage III and stage IV $(\mathrm{p}=0.120)$ fails to be significant. 

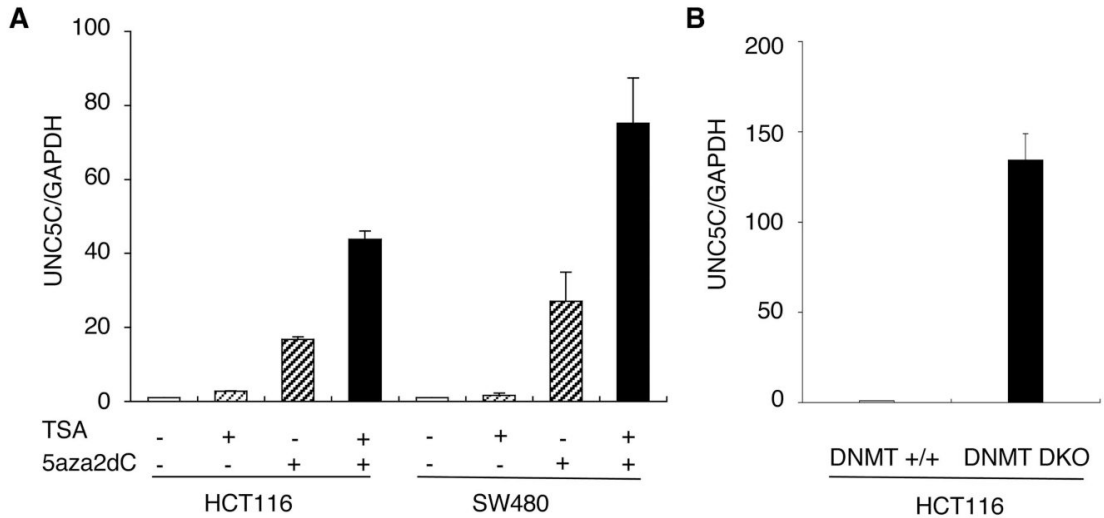

C

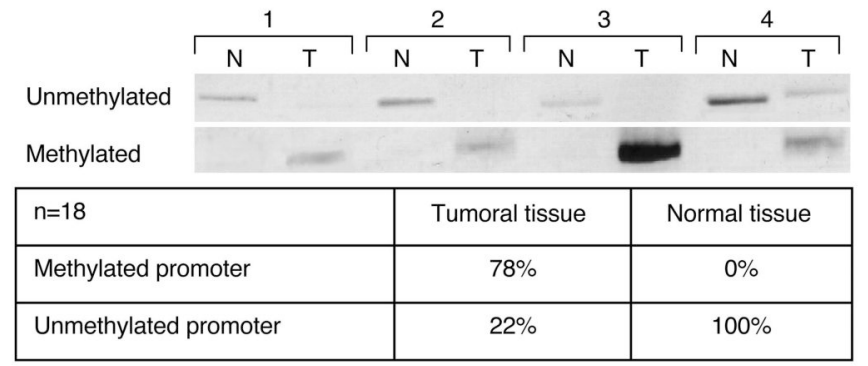

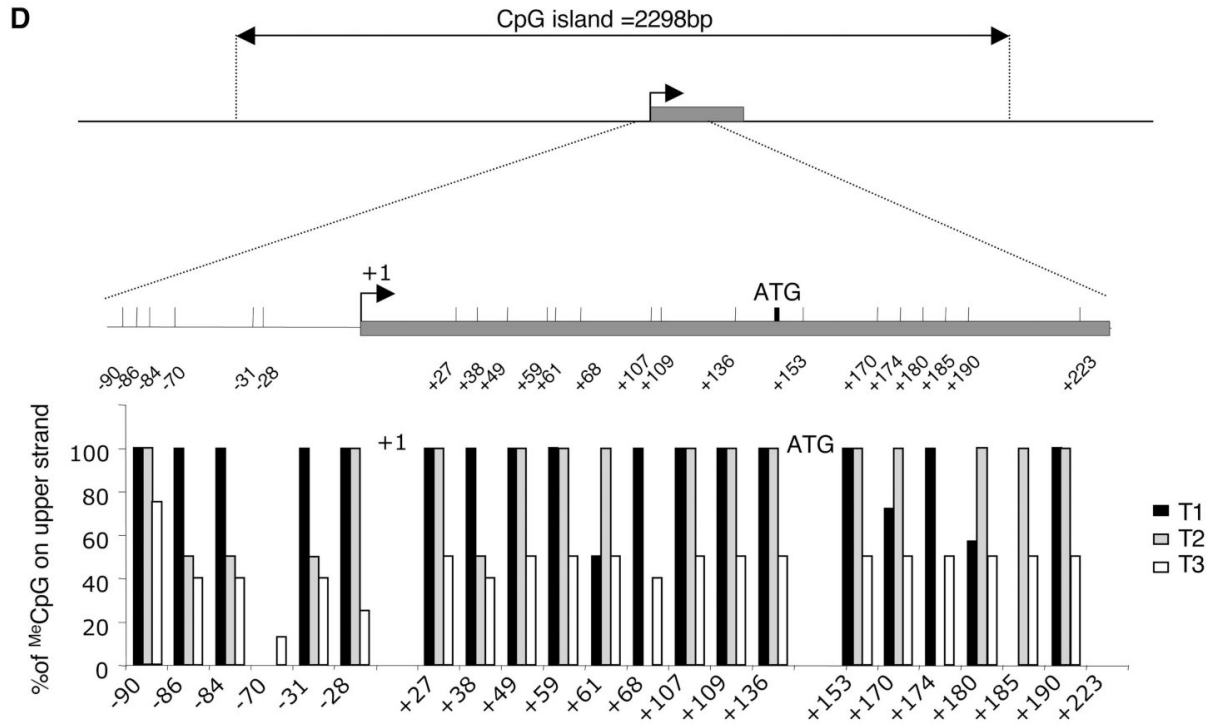

Figure 3. Epigenetic inactivation of UNC5C in human colorectal tumors

A, HCT116 and SW480 cells were treated with 5 $\mathrm{M}$ 5-Aza-2'-deoxycytidine (5aza2dc) for $48 \mathrm{H}$ and then with $0.3 \mu \mathrm{M}$ TSA for $24 \mathrm{H}$. Quantitative real-time RT-PCR was performed with UNC5C primers relatively to GAPDH, RXR $\alpha$ and PPIA, as explained in Fig.1. The expression level is presented as a ratio between UNC5C and GAPDH. B, UNC5C expression was compared in HCT116 versus HCT116 DKO for DNMT1 and $3 b^{24}$ by quantitative real-time RT-PCR, as described previously. C, Methylation-specific PCR (MSP) analysis of sodiumbisulfite-treated DNA from human colorectal biopsies of Normal tissues $(\mathrm{N})$ and Tumoral tissues (T). Amplification using primers that hybridize specifically on sequences of the UNC5C promoter that are Unmethylated and/or Methylated (data shown only for 4 different biopsies, 
biopsy 4 showing both the methylated and unmethylated states of the UNC5C promoter in tumoral tissue, whereas in the three others, UNC5C promoter is completely methylated in tumoral tissue). Compiled results on 18 human colorectal biopsies are presented in the table. D, Change in ${ }^{\mathrm{Me}} \mathrm{CpG}$ content in the region of the UNC5C promoter in three different tumors (T1,T2,T3). Upper: Representation of the DNA region surrounding the first exon (in grey) with transcriptional start site arrowed in black (Accession n ${ }^{\circ}$ NM_003728). The locus includes a

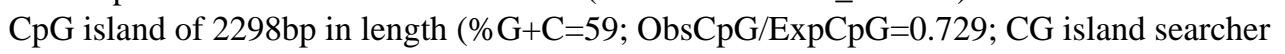
software). The region amplified by PCR primers is enlarged and the position of each $\mathrm{CpG}$ is indicated from the UNC5C transcription start site. Bottom: Ten PCR clones were sequenced from three different tumors (T1,T2,T3) and from the corresponding normal tissues (N1,N2,N3) (not shown as no methylation is detected) to determine the percentage of methylation at the CpG sites in the analysed region. 
A

\begin{tabular}{|c|c|c|c|c|c|c|}
\hline mice & $\begin{array}{c}\text { Nb of } \\
\text { mice }\end{array}$ & $\begin{array}{c}\text { Nb of } \\
\text { tumors per } \\
\text { mouse }\end{array}$ & Range & $\begin{array}{c}\text { Nb of } \\
\text { tumors }\end{array}$ & $\begin{array}{c}\text { Percentage } \\
\text { of low-grade } \\
\text { tumors }\end{array}$ & $\begin{array}{c}\text { Percentage of } \\
\text { high-grade tumors } \\
\text { (\% adenocarcinoma) }\end{array}$ \\
\hline $\mathrm{Apc}^{+/ 1638 \mathrm{~N}} \mathrm{UNC5C}^{+/+}$ & 15 & 1.13 & $0-3$ & 17 & 71 & $29(23)$ \\
\hline $\mathrm{Apc}^{+/ 1638 \mathrm{~N}} \mathrm{UNC5C}^{+/ \mathrm{rcm}}$ & 51 & 1.6 & $0-6$ & 83 & 43 & $57(33)$ \\
\hline $\mathrm{Apc}^{+/ 1638 \mathrm{~N}} \mathrm{UNC5C}^{\mathrm{rcm} / \mathrm{rcm}}$ & 19 & 1.6 & $0-4$ & 30 & 17 & $83(43)$ \\
\hline
\end{tabular}
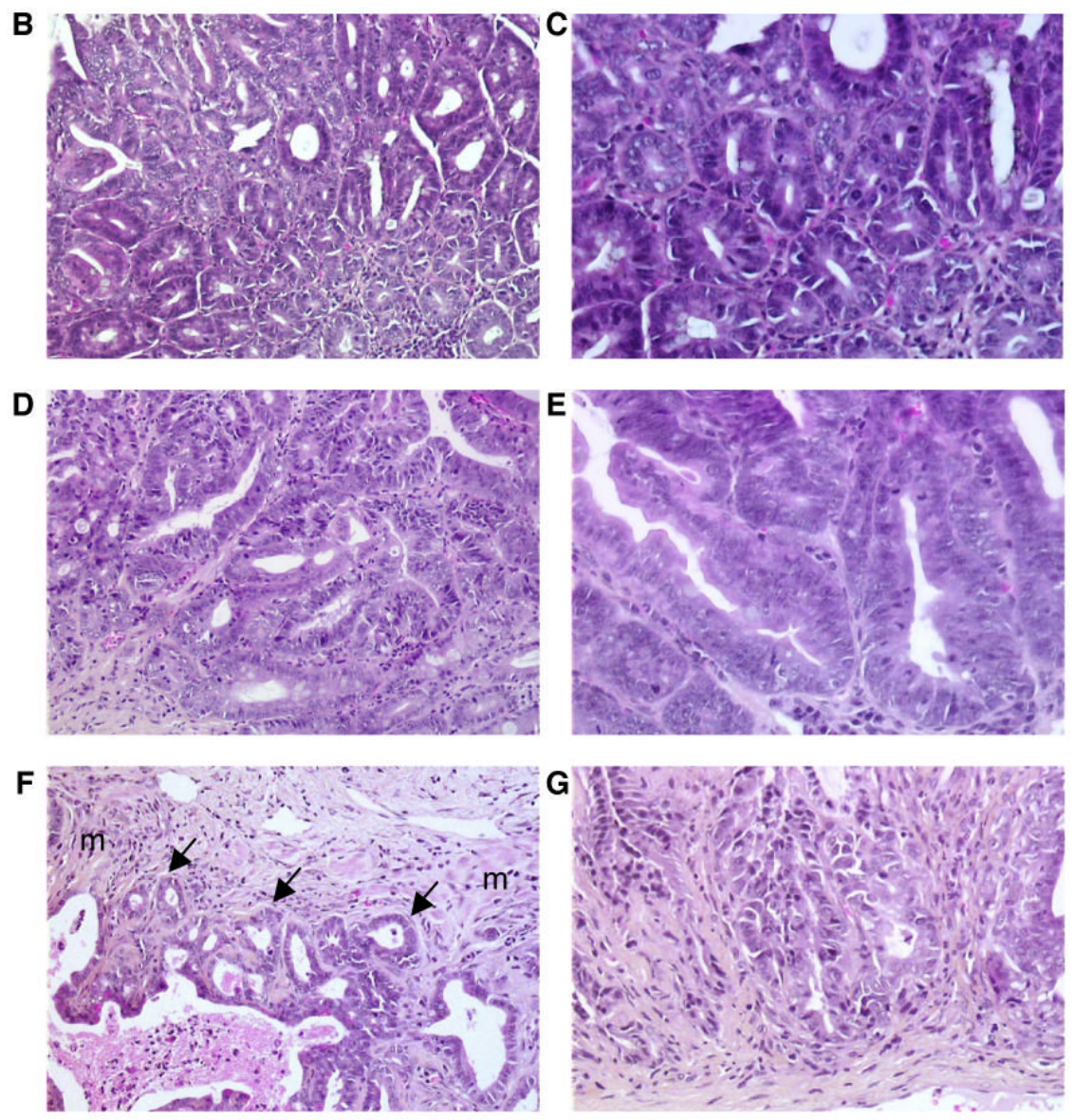

Figure 4. Increased intestinal tumor progression in UNC5C mutant mice UNC5 $\mathrm{C}^{\mathrm{rcm}}$ mice were backcrossed into an $\mathrm{Apc}^{1638 \mathrm{~N}}$ background and analysed for tumor development in 6 months old mice. A, Table showing the number $(\mathrm{Nb})$ of $\mathrm{Apc}^{+/ 1638 \mathrm{~N}}$ $\mathrm{UNC} 5 \mathrm{C}^{\mathrm{rcm} / \mathrm{rcm}}, \mathrm{Apc}^{+/ 1638 \mathrm{~N}} \mathrm{UNC} \mathrm{C}^{+/ \mathrm{rcm}}$ or Apc ${ }^{+/ 1638 \mathrm{~N}} \mathrm{UNC} \mathrm{C}^{+/+}$mice studied, the average number of tumors per mouse, the range, the number of tumor studied and the proportion of low-grade tumors and high-grade tumors including adenocarcinomas. Significance: $\chi^{2}$ test, p $<0.001$. B-G: representative lesions from Apc ${ }^{+/ 1638 N} \mathrm{UNC} 5 \mathrm{C}^{\mathrm{rcm} / \mathrm{rcm}}$ mice: low grade adenoma $(\mathbf{B}, \mathbf{C})$, high grade adenoma $(\mathbf{D}, \mathbf{E})$ and adenocarcinoma $(\mathbf{F}$, note the presence of muscularis (m) invasion indicated by arrows, $\mathbf{G})$. C,E, $\mathbf{G}$ enlargement of respectively $\mathbf{B}, \mathbf{D}, \mathbf{F}$, Original magnifications: B,D,F, X80; C,E,G, X250 


\begin{tabular}{|c|c|c|c|c|c|c|c|}
\hline \multirow{2}{*}{ A } & \multirow{2}{*}{ mice } & \multirow{2}{*}{ samples } & \multicolumn{4}{|c|}{$\%$ of samples with $\mathbf{n}$ apoptotic cells } & \multirow{2}{*}{$\begin{array}{l}\% \text { with } \\
\text { islets }\end{array}$} \\
\hline & & & $<2$ & $2-4$ & $5-6$ & $>6$ & \\
\hline \multirow{3}{*}{ Low-grade adenoma } & 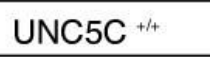 & 12 & 58 & 42 & 0 & 0 & 16.7 \\
\hline & UNC5C + $+\mathrm{rcm}$ & 15 & 73 & 27 & 0 & 0 & 0 \\
\hline & UNC5C remrem & 15 & 60 & 40 & 0 & 0 & 0 \\
\hline \multirow{3}{*}{ High-grade adenoma } & $\mathrm{UNC5C}^{+/+}$ & 15 & 47 & 53 & 0 & 0 & 6.7 \\
\hline & UNC5C +rem & 16 & 75 & 25 & 0 & 0 & 0 \\
\hline & UNC5C remrom & 15 & 87 & 13 & 0 & 0 & 0 \\
\hline \multirow{3}{*}{ Adenocarcinoma } & $\mathrm{UNC} \mathrm{C}+/+$ & 12 & 0 & 33 & 25 & 42 & 75 \\
\hline & UNC5C +rem & 12 & 17 & 50 & 25 & 8 & 25 \\
\hline & UNC5C $\mathrm{rcm} / \mathrm{rm}^{-}$ & 12 & 25 & 42 & 33 & 0 & 8.3 \\
\hline
\end{tabular}
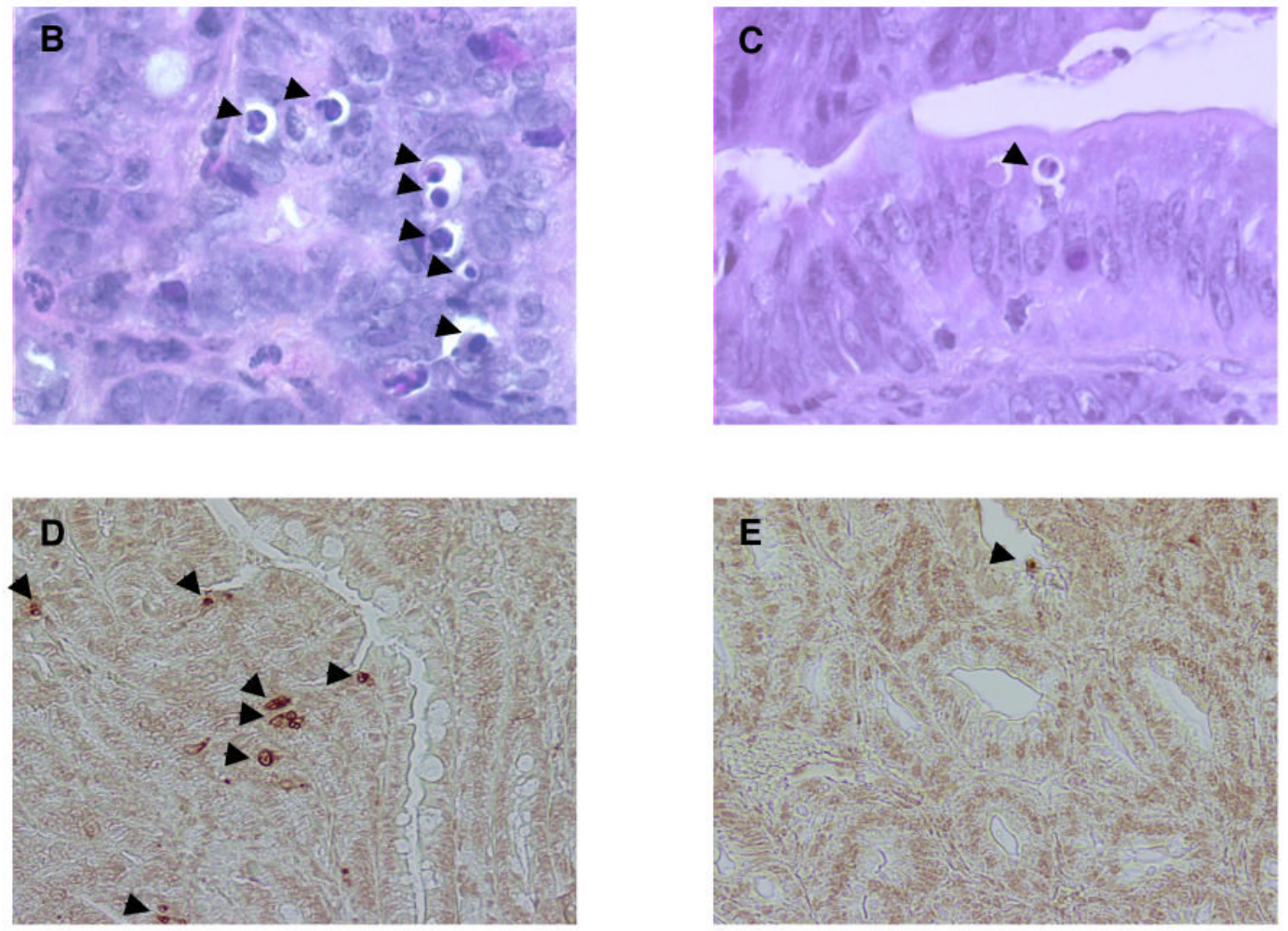

Figure 5. Tumors from UNC5C mutant mice are less prone to apoptosis

A, Table showing the number of apoptotic cells per section of tumors (sample) issued from $\mathrm{Apc}^{+/ 1638 \mathrm{~N}} \mathrm{UNC}^{5 C^{+/+}}$mice, $\mathrm{Apc}^{+/ 1638 \mathrm{~N}} \mathrm{UNC} \mathrm{C}^{+/ \mathrm{rcm}}$ or Apc ${ }^{+/ 1638 \mathrm{~N}} \mathrm{UNC}^{\mathrm{rcm} / \mathrm{rcm}} . \mathbf{B}, \mathbf{C}$, Representative microscopic images from adenocarcinoma from either $\mathrm{Apc}^{+/ 1638 \mathrm{~N}}$ $\mathrm{UNC} \mathrm{C}^{+/+}(\mathbf{B})$ or $\mathrm{Apc}^{+/ 1638 \mathrm{~N}} \mathrm{UNC} \mathrm{C}^{\mathrm{rcm} / \mathrm{rcm}}(\mathbf{C})$ mice. Note in adenocarcinomas from $\mathrm{Apc}^{+/ 1638 \mathrm{~N}} \mathrm{UNC} \mathrm{C}^{+/+}$mice, the presence of several (more than 3 ) apoptotic cells side by side that form islets of apoptotic cells. Apoptotic cells are shown by arrows. Original magnifications: X450. D,E, similar as in B, C except that TUNEL staining was performed as described in the Experimental procedures section. 